\title{
OUVIDORIA E A EDUCAÇÃO CORPORATIVA: SISTEMATIZANDO AS AFINIDADES
}

\author{
Maria Lumena Balaben Sampaio ${ }^{1}$ \\ Kelly Alves Prado²
}

\begin{abstract}
Resumo
O presente artigo tem o objetivo de indicar os pontos de convergência entre a atuação das Ouvidorias e a adoção da educação corporativa como ferramenta que potencializa resultados na organização, seja ela pública ou privada. Sistematizando as afinidades a partir das competências do Ouvidor, é possível delinear ações estruturadas que contribuam para o desenvolvimento humano dos colaboradores e que, por consequência, se refletirão nos relacionamentos internos e externos e na entrega de melhores serviços. A qualidade percebida pela interação entre Ouvidoria e educação corporativa se expande porque também indicará um compromisso do gestor com a ética e a responsabilidade social.
\end{abstract}

Palavras-chave: Ouvidoria Pública e Privada. Educação Corporativa. Competências.

\begin{abstract}
This article aims to indicate the points of convergence between the activities of the Ombudsman and the adoption of corporate education as a tool that enhances results in the organization, whether public or private. By systematizing the affinities, from the competencies of the Ombudsman, it is possible to delineate structured actions that contribute to the human development of the employees, which will consequently be reflected in internal and external relationships and in the delivery of better services. The quality perceived by this interaction, Ombudsmanship and corporate education, expands because it will also indicate a manager's commitment to ethics and social responsibility.
\end{abstract}

Keywords: Public and Private Ombudsman's Office. Corporate Education. Skills.

DOI:10.37814/2594-5068.2019v2.p71-77

1 Advogada, especialista em Gestão Pública, certificada em Ouvidoria pela Unicamp, certificada em mediação de conflitos pela USF (Universidade São Francisco), Ouvidora-Geral do Município de São Paulo.

2 Publicitária, especialista em Gestão Estratégica de Pessoas (Universidade Presbiteriana Mackenzie).

Certificada em Ouvidoria pela ABO (Associação Brasileira de Ouvidores/Ombudsman) e Mediação de Conflitos pela USF. Foi assessora técnica na Ouvidoria-Geral do Município de São Paulo e Ouvidora-Geral do Hospital das Clínicas (HCFMUSP). (kelly.alpr@gmail.com) 


\section{INTRODUÇÃO}

O Ministério do Trabalho e Emprego atualizou a Classificação Brasileira de Ocupações com um impacto direto na função de Ouvidor. A Classificação Brasileira de Ocupações descreve e ordena as ocupações dentro de uma estrutura hierarquizada que permite agregar as informações referentes à força de trabalho segundo características ocupacionais que dizem respeito à natureza da força de trabalho (funções, tarefas e obrigações que tipificam a ocupação) e ao conteúdo do trabalho (conjunto de conhecimentos, habilidades, atributos pessoais e outros requisitos exigidos para o exercício da ocupação).

A Classificação Brasileira de Ocupações - CBO, instituída pela Portaria Ministerial $n^{\circ} 397$, de 9 de outubro de 2002, tem por finalidade a identificação das ocupações no mercado de trabalho para fins classificatórios nos registros administrativos e domiciliares.

O impacto consistiu em que Ouvidor/Ombudsman passou de componente da família da "comunicação" ao lado de publicitários, por exemplo, para a família do "gerenciamento".

Atualmente, o Ouvidor se identifica na CBO pelo código 1423-40, que tem entre outras atividades "elaborar planos estratégicos das áreas de negócios e de relacionamentos". Consolida, portanto, o fundamento da Ouvidoria como unidade organizacional estratégica.

Para desempenho de suas atividades, o Ouvidor deve apresentar competências individuais que viabilizem a Ouvidoria como ferramenta de gestão, tais como: sugerir melhorias dos serviços de atendimento aos cidadãos; mediar conflitos; administrar conflitos entre as partes; realizar escuta ativa, analisar demanda reclamatória; encaminhar solicitações aos responsáveis; dar retorno aos públicos (feedback); e participar da elaboração de projetos educacionais.

É de interesse no presente artigo dar ênfase à participação do Ouvidor na elaboração de projetos educacionais, o que nos leva à seguinte indagação: por que foi incluída essa competência na CBO?

Justifica-se, por conseguinte, a busca de elementos que ofereçam uma resposta. Eis a relevância do tema.

\section{DESENVOLVIMENTO}

\subsection{A Contribuição do Ouvidor para a Educação Corporativa}

A educação corporativa possibilita a aprendizagem contínua dos funcionários de acordo com os objetivos estratégicos da organização e está relacionada diretamente ao processo de inovação.

Educação corporativa é um sistema de formação de pessoas pautado por uma gestão de pessoas com base em competências, devendo portanto instalar e desenvolver nos colaboradores (internos e externos) as competências consideradas críticas para a viabilização das estratégias de negócio, promovendo um processo de aprendizagem ativo e permanente vinculado aos propósitos, valores, objetivos e metas empresariais. (EBOLI, 2004) 
Na proposta de identificar os elementos que justifiquem a presença do Ouvidor como um dos protagonistas de projetos educacionais, é necessário, contudo, que se estabeleçam premissas de senso comum do que venha a ser um projeto educacional nas organizações.

Previamente há que se entender que: "o trabalho por projeto não é solitário, ele exige uma postura colaborativa entre as pessoas envolvidas. O projeto constitui-se em um trabalho em grupo, de formação de um time, em que as pessoas, cada qual com seus talentos, se relacionam em direção a um alvo em comum" (PRADO, 2005, p. 57).

De acordo com a área de atuação em que o Ouvidor está inserido, é importante que avalie de acordo com os indicadores quais são as necessidades do treinamento para um projeto educacional; sobre o que precisa ser melhorado, treinado ou desenvolvido, juntamente com os gestores. Segundo MENESES, ZERBINI e ABBAD (2010, p. 29):

[...] os processos de avaliação de necessidades educacionais passam a ser considerados importantes instrumentos de gestão da aprendizagem humana. A partir de processos dessa natureza, bem planejados e conduzidos, torna-se possível aproximar as ações educacionais dos objetivos organizacionais e, consequentemente, conferir um caráter estratégico às áreas responsáveis pela promoção do desenvolvimento humano em contextos organizacionais.

Nas ações de treinamento, segundo BORGES (2005), também é importante descrever quais são os comportamentos desejados, pois eles irão consequentemente construir os objetivos e os conhecimentos, as habilidades e as atitudes correspondentes; e, a partir disso, os conteúdos serão ministrados.

No caso do desenvolvimento de pessoas, o resultado é obtido a longo prazo, considerando que prepara o colaborador para a sua carreira profissional, não apenas em treinamento para uma função específica. Dentre as necessidades de treinamento, podem estar relacionadas: melhoria do conhecimento técnico dos colaboradores, habilidades e atitudes, comportamento interpessoal com os clientes ou usuários do serviço etc.

Quando acrescentamos ao conceito de projeto o adjetivo educacional, encontramos a seguinte referência:

\begin{abstract}
São inúmeras as atividades humanas nas quais, atualmente, a ideia de projetos educacionais está colocada como uma nova forma de organizar e realizar as atividades profissionais. Profissionais dotados de maior autonomia para tomar decisões, valorização do trabalho em grupo, desenvolvimento de vínculos de solidariedade e aprendizado constante são algumas das características incentivadas pela realização de projetos educacionais. Em uma equipe que trabalha com vistas a realizar um projeto, são mais importantes a solidariedade e o cuidado com a contribuição de cada um para o todo do que os níveis hierárquicos.
\end{abstract}

Nesse contexto, para a construção de equipes de alto desempenho, todos os membros devem estar engajados no cumprimento da tarefa de acordo com seus objetivos em comum. A questão não é quem manda em quem, mas se o projeto está se tornando realidade.

Assim, pode-se dizer que a noção corrente de projeto educacional contempla dois elementos fundamentais: trabalho colaborativo, posto que é fruto de uma equipe, e objetivo de desenvolvimento profissional. 
Essa premissa nem sempre está presente. Muitas organizações se dedicam ao treinamento ou capacitação para atingir determinado objetivo imediato ou satisfazer uma necessidade normativa. Há uma temporalidade de acordo com a satisfação de necessidades sazonais ou em resposta à pressão de demandas do Poder Público, da imprensa, dos cidadãos, entre outras.

O contexto social na contemporaneidade exige uma postura competitiva, o que levou muitas organizações à percepção de que estruturar unidades de educação corporativa, conhecidas também como Universidades Corporativas, significa não só um diferencial como também uma correspondência às boas práticas de governança.

\subsection{A Atuação do Ouvidor nas Universidades Corporativas}

As universidades corporativas se caracterizam pelo aprendizado formal, têm como princípio básico manter os funcionários atualizados e funcionam pelos seguintes meios: educação presencial, semipresencial e educação a distância (EAD) - que é transmitida por um ambiente virtual, com mais possibilidades de escolha em relação ao tempo e local de acesso.

Segundo ANTONELLO et al. (2011, p. 251), "[...] a aprendizagem formal oferece condições de otimizar os processos de aquisição, retenção e generalização do conhecimento, habilidades e atitudes".

A esse respeito nos ensina João Carlos LOPES: "Universidade corporativa torna-se fator estratégico para o desenvolvimento e educação de funcionários, clientes e fornecedores, com o objetivo de atender às estratégias empresariais de uma organização. Há variedade na terminologia empregada em torno da ideia da educação continuada, que se fundamenta numa interpretação da educação como um processo que deve prolongar-se durante a vida adulta. Educação permanente, formação permanente, educação continuada, educação contínua, requalificação profissional e desenvolvimento profissional são termos em torno de um mesmo núcleo de preocupação. A educação continuada consiste em um processo de aperfeiçoamento e atualização de conhecimentos, visando melhorar a capacitação técnica e cultural do profissional”. Segundo MUNDIM (2002), "[...] Educação corporativa é, portanto, o conjunto de práticas educacionais planejadas para promover oportunidades de desenvolvimento do funcionário, com a finalidade de ajudá-lo a atuar mais efetiva e eficazmente na sua vida institucional".

Nesta linha lógica, importante lembrar as características pelas quais uma Ouvidoria se destaca no cumprimento da missão da organização: é a arquiteta da inovação. A Ouvidoria, por meio de uma escuta ativa, catalisa os conflitos entre os relacionamentos tanto internos como externos, promove os devidos encaminhamentos para mitigar esses conflitos, bem como confere um tratamento aos dados estatísticos sob sua coordenação, transformando-os em informações estratégicas.

Portanto, o Ouvidor é um agente de mudança, é aquele que antecipa tendências e propõe medidas que objetivam a melhoria contínua da organização. É necessária uma atualização de conhecimento constante, um desenvolvimento contínuo dos colaboradores. Enquanto instância de participação e controle social, a Ouvidoria deve absorver as demandas para estruturar formas, ações, simplificações nos processos da organização, constituindo-se em unidade que promove a 
devolutiva àqueles cidadãos que lhe entregaram reclamações, sugestões, denúncias representativas da sociedade.

Traçam-se assim dois pontos de interface entre a atuação da Ouvidoria e da Educação Corporativa: união para construir uma visão compartilhada da organização e a conexão com a realidade social. O gestor máximo deve estar envolvido em ambas, mas é imprescindível que todos os níveis da organização, seja pública ou privada, estejam em sintonia; que haja coesão da equipe em torno do propósito de transparência e ética nos relacionamentos. Esses são valores com os quais a sociedade mais do que se identifica, exige.

Outro aspecto a ser abordado é a competência individual como ponto de interface. Há que se reforçar a noção de competência estabelecida pela CBO - Classificação Brasileira de Ocupações para os profissionais que atuam como Ouvidores. Participar na elaboração de projetos educacionais funciona, na prática, como um guardião das bases da organização, seus valores e alinhamento com a missão e visão da organização.

Acrescente-se que muitas regulamentações de Ouvidorias exigem a capacitação e certificação em Ouvidoria. No estado de São Paulo, no art.10 do Decreto 60.399/2014, há disposição expressa que estabelece a formação em nível superior e a certificação por entidade reconhecida como requisito para a função de Ouvidor. Seguindo essa diretriz, pode ser citada a Resolução 4.433/2015 do Banco Central do Brasil, que dedicou o Capítulo VII à Certificação. Logo, houve destaque à necessidade de competências específicas para a atuação de Ouvidor, estabelecendo um conteúdo programático mínimo para a certificação e regras para a avaliação e concessão de certificação.

A ABO, Associação Brasileira de Ouvidores/Ombudsman, em 2011, após uma ampla discussão com as seccionais, estabeleceu e publicou em seu site o Regulamento para a capacitação e certificação em Ouvidorias Públicas e Privadas. Há que se ressaltar que o documento consolidou a prática da Associação em ministrar cursos desde o início de sua criação. Sendo uma associação profissional, é decorrência imperativa a qualificação e aprimoramento daqueles que atuam como Ouvidores, nas Ouvidorias ou em atividades correlatas como os núcleos organizacionais que se relacionam com o cidadão ou o consumidor. Essa obrigatoriedade se constitui numa ferramenta de controle de qualidade para os profissionais que atuam na temática.

Da mesma forma, a educação corporativa estruturada se alinha ao objetivo de desenvolvimento da competência individual do colaborador. Mais uma vez, João Carlos LOPES nos esclarece que:

O principal objetivo da educação corporativa é evitar que o profissional se desatualize técnica, cultural e profissionalmente e perca sua capacidade de exercer a profissão com competência e eficiência, causando desprestígio à profissão, além do sentimento de incapacidade profissional. Educação corporativa é, portanto, o conjunto de práticas educacionais planejadas para promover oportunidades de desenvolvimento do funcionário, com a finalidade de ajudá-lo a atuar mais efetiva e eficazmente na sua vida institucional.

\section{CONSIDERAÇÕES FINAIS}

Por todo o exposto, chega-se à conclusão de que o Ouvidor deve, entre as dimensões de 
sua competência, participar da elaboração de projetos educacionais. Tem contribuição fundamental para o alinhamento dos colaboradores com a missão da organização.

É um poderoso aliado das Universidades Corporativas, como também elemento que promove talentos e desenvolvimento do capital humano das organizações.

As interações da ABO Nacional com Ouvidores e organizações que buscam a capacitação e certificação para seus colaboradores sinalizam que há pouca ou quase nula interlocução entre a Ouvidoria e a Universidade Corporativa.

Nesse ponto há expertise ímpar da ABO Nacional, que se dedica a disseminar conhecimento entre seus associados e aos profissionais de maneira geral. Ela estabeleceu as bases para a certificação internalizando as evoluções social, econômica e política que impactaram a atuação das Ouvidorias. Dito de outra forma, a atuação da Associação propiciou captar as mudanças das relações sociais incorporando ao plano de ensino conteúdo programático que se constituísse em ferramenta para o profissional em sua atuação cotidiana. Ao longo de mais de vinte anos, portanto, o conteúdo foi revisto e atualizado de acordo com as exigências contextuais dos Ouvidores. Exemplifique-se pela introdução do módulo de mediação de conflitos nos cursos de capacitação e certificação a partir de 2007. Importante discussão que, em certa medida, contribuiu para a representação institucional em outros fóruns de debates que, ao final, culminaram com a Lei 13.140/2015, que disciplina a mediação de conflitos extrajudicial. A elaboração de um curso básico de capacitação e certificação em Ouvidoria, promovido pela $\mathrm{ABO}$ Nacional, se constitui num marco regulatório das competências do Ouvidor, incluindo os fundamentos do instituto da Ouvidoria e também disciplinas que despontaram de exigências de mercado para a atuação dos Ouvidores. Corolário do curso é o Regulamento da Certificação, que prevê uma avaliação de impacto para identificar a assimilação dos conteúdos e aptidão para o desempenho da função.

Assim, constata-se que a proximidade do Ouvidor a seus pares fortalece o eixo profissional de tal forma que a partir do curso básico surgiram os cursos in company. Cristalina a conclusão de que os Ouvidores que se articulam com as respectivas unidades de educação corporativa, seja em âmbito público ou privado, tanto viabilizam melhorias para a evolução funcional como contribuem decisivamente para o reconhecimento do instituto da Ouvidoria como espaço onde o cidadão tem a garantia de direitos.

\section{REFERÊNCIAS}

ANTONELLO, C. S. et al. Aprendizagem organizacional no Brasil. Porto Alegre: Bookman, 2011.

BANCO CENTRAL DO BRASIL. Resolução n 4.433, de 23 de julho de 2015. Dispõe sobre a constituição e o funcionamento de componente organizacional de Ouvidoria pelas instituições financeiras e demais instituições autorizadas a funcionar pelo Banco Central do Brasil. Disponível em: <http://www.bcb.gov.br/pre/normativos/res/2015/pdf/ res_4433_v1_O.pdf>. Acesso em: 02 jun. 2018.

BORGES-ANDRADE, J. E.; ABBAD, G. S.; MOURÃO, L. (Org.) et al. Treinamento, desenvolvimento e educação em organizações e trabalho. Porto Alegre: Bookman, 2005.

BRASIL. Ministério do Trabalho. Classificação brasileira de ocupações. Brasília. Disponível em: <http://www.mtecbo. gov.br/cbosite/pages/home.jsf>. Acesso em: 02 jun. 2018. 
Lei $n^{\circ} 13.140$, de 26 de junho de 2015. Dispõe sobre a mediação entre particulares como meio de solução de controvérsias e sobre a autocomposição de conflitos no âmbito da Administração Pública; altera a Lei no 9.469, de 10 de julho de 1997, e o Decreto $n^{\circ} 70.235$, de 6 de março de 1972; e revoga o $\S 2^{\circ}$ do art. $6^{\circ}$ da Lei $n^{\circ} 9.469$, de 10 de julho de 1997. Diário Oficial da União, Brasília, 26 de junho de 2015. Disponível em: <http://www.planalto.gov.br/ ccivil_03/_ato2015-2018/2015/lei/L13140.htm>. Acesso em: 19 jun. 2018.

EBOLI, M. Educação corporativa no Brasil: mitos e verdades. São Paulo: Gente, 2004.

LOPES, João Carlos. Educação corporativa. Disponível em: <http://www.rhportal.com.br/artigos-rh/educao-corporatival>. Acesso em: em 02 jun. 2018.

MENESES, P.; ZERBINI, T.; ABBAD, G. Manual de treinamento organizacional. Porto Alegre: Bookman, 2010.

MUNDIM, Ana Paula Freitas. Desenvolvimento de produtos e educação corporativa. São Paulo: Atlas, 2002.

PORTAL EDUCAÇÃO. Projetos educacionais. Disponível em: <https://www.portaleducacao.com.br/conteudo/artigos/ pedagogia/projetoseducacionais/8012>. Acesso em: 02 jun. 2018.

PRADO, M. E. B. B. Articulações entre áreas de conhecimento e tecnologia. Articulando saberes e transformando a prática. In: ALMEIDA, M. E. B. de; MORAN, J. M. (Org.). Integração das tecnologias na educação. Brasília: Ministério da Educação/SEED/TV Escola/Salto para o Futuro, 2005. Disponível em: <http://www.virtual.ufc.br/cursouca/modulo_4_projetos/conteudo/unidade_1/Eixo1-Texto12.pdf>. Acesso em: 02 jun. 2018.

SÃO PAULO (Estado). Decreto n 60.399, de 19 de abril de 2014. Dispõe sobre a atividade das Ouvidorias instituídas pela Lei $n^{\circ} 10.294$, de 20 de abril de 1999. Disponível em: <https://www.al.sp.gov.br/repositorio/legislacao/decreto/2014/decreto-60399-29.04.2014.html>. Acesso em: 19 jun. 2018. 